\title{
Evaluation of chemical and mechanical resistance of virgin and recycled poly (ethylene terephthalate) and poly(methylene oxide) when applied as gravel pack in petroleum wells
}

\author{
Alexandre Zacarias Ignácio Pereira* and Marcia Cerqueira Delpech² \\ ${ }^{1}$ Petróleo Brasileiro S.A. - PETROBRAS, Rio de Janeiro, RJ, Brazil \\ IInstituto de Química - IQ, Universidade do Estado do Rio de Janeiro - UERJ, Rio de Janeiro, RJ, Brazil \\ *alexandre.zip@petrobras.com.br
}

\begin{abstract}
Nowadays more and more unexpected uses for common materials have been observed, especially when recycled polymers are concerned. In this work, the viability for application of virgin and recycled poly(ethylene terephthalate) $\left(\mathrm{PET}_{\text {vir }}\right.$ and $\mathrm{PET}_{\text {rec }}$, respectively) and also poly(methylene oxide) (PMO) as granular materials (gravel) for gravel packing in sand control systems for unconsolidated sandstone reservoirs was studied. Polymer samples were tested in conditions similar to those observed in Campos Basin sandstone formations, in Brazilian Southwest $\left(70{ }^{\circ} \mathrm{C}\right.$ and $\left.24.1 \mathrm{MPa}\right)$. Samples were individually confined in roller cells with chemicals used in formation treatment: hydrochloric acid, pentapotassic DTPA salt (chelant Trilon CK) and in a mixture of diesel, xylene and butyl glycol. Mass loss was measured and the changes in molecular mass verified by size exclusion chromatography (SEC). Physical shape and grain size distribution were verified by scanning electron microscopy (SEM) and sieving tests. The effects over the polymeric gravel pack confinement resistance and permeability were evaluated using an API permeability cell. PMO proved to have a limited use, whereas $\mathrm{PET}_{\text {rec }}$ and $\mathrm{PET}_{\text {vir }}$ samples were not significantly affected, suggesting the viability of applying that recycled polymer in gravel packing for sand control in petroleum wells.
\end{abstract}

Keywords: poly(ethylene terephthalate), recycled polymer, poly(methylene oxide), gravel pack, chemical resistance, sand control, oil well.

\section{Introduction}

Polymers are highly versatile materials. In fact, their application is virtually unlimited, once the industry development is always facing new problems and, therefore, demanding new solutions that results in novel ways of using those substances. This is the case of the oil industry, where polymers can be found everywhere, from simple sealing rings to complex platform turrets. One of those new proposed applications is in oil well building, where conventional polymers, as poly(ethylene terephthalate) (PET) and poly(methylene oxide) (PMO) can find new unexpected uses as, for example, granular materials (gravel) in underground sand filters (gravel packs). Moreover, even recycled PET has the necessary characteristics to be used in the same way, once its properties were found to be similar to the virgin material, potentially opening a new front for polymer recycling ${ }^{[1]}$.

Is important to notice that the main Brazilian oil fields are composed by mechanically fragile sandstone formations ${ }^{[2,3]}$, meaning that all the wells installed in those fields need to be equipped with some kind of sand control system to prevent the contamination of the oil production with sand. Sand filters, composed of metallic screens and granular materials, are known as gravel packs ${ }^{[4-6]}$ and have been the usual choice for the last two decades. Typically the granular gravel employed in those operations is basically an inorganic compound, such as sand, sintered ceramic or

sintered bauxite. Despite their chemical resistance, those inorganic compounds have high density, which brings difficulties to install the gravel pack. Besides that, they cannot be shaped, have dispersed size distribution and are relatively costly, problems that can be overcome by replacing them by polymeric materials such PET or PMO.

A previous work ${ }^{[1]}$, where PET and PMO were exposed to seawater and petroleum environments, already has shown the good potential for those polymers as gravel packs. Nevertheless, an exposition of these polymers, to more aggressive media which simulates conditions that polymers would have to face when used for gravel packing oil producers or water injection wells, is still needed.

The purpose of this work is evaluate chemical and mechanical resistance of virgin and recycled PET and virgin PMO, when exposed to different aggressive liquid media, commonly used to treat formations, in a simulated oil well environment. Test parameters (temperature and pressure of the medium, as well as time of exposure to chemicals) were defined to match the observed treatment conditions. The chemicals were chosen according to those employed in Campos Basin, in offshore Brazilian Southwest.

This work provides a systematic test pattern that compensates the lack of standard tests of the American Petroleum Institute (API) for polymeric materials to be applied as gravel pack in sand control systems. 


\section{Experimental}

\subsection{Materials}

Virgin and recycled poly(ethylene terephthalate) $\left(\mathrm{PET}_{\mathrm{vir}}\right.$ and $\mathrm{PET}_{\text {rec }}$, respectively) were employed as received from Recipet Revalorização de Produtos LTDA, avoiding to introduce new process variables in the test. Poly(methylene oxide) (PMO) was supplied by ICO Polymers Global. The products used in the chemical tests were: hydrochloric acid $(\mathrm{HCl})$, from Vetec Química Fina Ltda.; chelating agent triamino diethylene penta potassium acetate (DTPA pentapotassium salt) (Trilon CK), from BASF do Brasil S.A.; and the solvents: 2-butoxyethanol (butyl glycol), from Oxiteno S.A., automotive diesel, from PETROBRAS S.A. and xylene, from Vetec Química Fina Ltda.

All polymer samples were characterized, prior to chemical exposure and after that, by size exclusion chromatography (SEC), scanning electron microscopy (SEM) and grains pack permeability, described hereafter.

\subsection{Evaluation of the chemical resistance}

After characterization, polymer samples $\left(\mathrm{PET}_{\mathrm{vir}}, \mathrm{PET}_{\mathrm{re}}\right.$ and $\mathrm{PMO}$ ) were placed inside individual cells made of steel N316 and Hastelloy C276, prototypes developed by PETROBRAS ${ }^{[1]}$. Each cell, with capacity for $443 \mathrm{~mL}$ each, was filled with $300 \mathrm{~g}$ of the polymeric samples and the respective liquid medium. Test pressure and temperature $\left(24.1 \mathrm{MPa}\right.$ and $\left.70^{\circ} \mathrm{C}\right)$ were chosen to match the hydrostatic and thermal conditions observed at formations located at $3.500 \mathrm{~m}$ depth, in Campus Basin, normally subjected to sand control. To avoid significant temperature and pressure variations during the tests, cells, polymer samples and liquids were heated to the test temperature $\left(70^{\circ} \mathrm{C}\right)$ prior to the confinement and the pressurization process. Pressure tests were made just before cells closing to verify sealing conditions. To prevent stagnation and intensify the contact of the polymer grains with the liquid medium cells were placed inside a roller oven and subjected to constant and uninterrupted axial rotation of $50 \mathrm{rpm}$ at test temperature.

Each test was performed filling the cells with just one type of chemical product at a time: hydrochloric acid $(\mathrm{HCl})$ $15 \%$, DTPA penta potassium salt (Trilon CK) $10 \%$ and a mixture of diesel (45\%), xylene (45\%) and butyl glycol (10\%). Exposure periods were chosen considering the maximum exposure time expected during chemical treatments usually performed in wells $\mathrm{s}^{[7,8]}: 24 \mathrm{~h}$ for acid and solvents mixture and $96 \mathrm{~h}$ for Trilon CK. After the exposure period, the samples were washed with neutral detergent and running water onto a metal sieve of $250 \mu \mathrm{m}$ Mesh size (thin enough to avoid significant loss of polymer fragments) vacuum dried at $70{ }^{\circ} \mathrm{C}$ for $24 \mathrm{~h}$, and then weighed.

\subsection{Characterization}

\subsubsection{Granulometry}

The determination of the polymer samples particle size was performed in a sieve shaker Produtest, model 4062, equipped with six sieves, ranging from 2 to 14 Mesh (apertures from 4.75 to $1.20 \mathrm{~mm}$ ) assembled vertically in decreasing Mesh size. Samples of $40 \mathrm{~g}$ were taken, before and after the chemical exposure. Samples were washed, dried and then subjected to agitation for $10 \mathrm{~min}$ in the sieve shaker, using the shaking intensity 9 . The polymer mass retained in each sieve was measured by differential weighing.

\subsubsection{Mechanical resistance of the polymeric gravel pack}

The mechanical strength of the polymeric gravel pack was evaluated using an API permeability cell ${ }^{[1]}$, according to API standards for granular agents applied in gravel packing operations ${ }^{[9,10]}$. A thin layer of polymer grains was disposed in the cell and then compressed at $13.8 \mathrm{MPa}$ and $70{ }^{\circ} \mathrm{C}$ simulating the confinement stress over a gravel pack system observed in oil wells. Mineral oil was flown through the grain layer to determine its permeability. The permeability behavior was taken as a measure of the polymeric gravel pack mechanical resistance to the oil well conditions.

\subsubsection{Size exclusion chromatography (SEC)}

Number and weight average molecular mass and polydispersity values of $\mathrm{PET}_{\text {vir }}, \mathrm{PET}_{\text {rec }}$ and PMO samples were determined employing size exclusion chromatography (SEC) technique. HFIP (1,1,1,3,3,3-hexafluoro-2-propanol) was the solvent employed for sample solutions $(0.1 \% \mathrm{~m} / \mathrm{v})$ and the mobile phase used in a chromatographer Waters 600 equipped with 2 columns Shodex HFIP 803 and 805, at $35^{\circ} \mathrm{C}$, at a flow rate of $1.0 \mathrm{~mL} / \mathrm{min}$.

Non-exposed samples were firstly analyzed. During the exposure to chemicals, samples were collected from the rolling cells and analyzed after the exposure period, in order to verify possible chemical degradation factors reflected in molecular weight and/or polydispersity.

\subsubsection{Scanning electronic microscopy (SEM)}

Scanning electronic microscopy (SEM) observation was performed in a Jeol JSM 6460 LV microscope in a magnification range varying from 25 to $100 x$. Samples were coated with a $200 \AA$ gold-palladium in an Eduards SIX vacuum metallizer. All micrographs were taken at $25 \mathrm{~mm}$, through secondary electron imaging, under an accelerating voltage of $20.0 \mathrm{keV}$.

\section{Results and Discussion}

\subsection{Mass loss and granulometry}

Table 1 shows that mass loss produced by chemical exposure was negligible in the case of exposure to solvents and Trilon $\mathrm{CK}^{[11-13]}$, but the exposure to acid caused an appreciable mass loss in all samples ${ }^{[12-15]}$. A comparison with other conventional gravel pack materials revealed that both recycled and virgin PET, exhibited mass changes close to the observed for those products in similar tests with the same substances ${ }^{[9,10]}$. PMO, however, suffered a mass loss much higher than PET when exposed to $\mathrm{HCl}^{[16-18]}$, resulting in mechanical integrity failure of its grains, proving, therefore, to be unacceptable for the proposed application.

The granulometry results presented in the Figure 1 demonstrate that neither virgin nor recycled PET were significantly affected by the chemical exposure. PMO samples behave in the same way when exposed to solvents or Trilon CK. However, the exposure to $\mathrm{HCl}$ greatly compromised PMO mechanical integrity, so its grains could 
not be measured after acid exposure. Virgin PET showed no significant variation in granulometric curve. The recycled polymer particle size, before and after the exposure tests, showed a more significant variation when compared to the virgin one, but the formation of fine fractions, resulting from grain fragmentation was not observed, indicating that the integrity of the recycled material was preserved. It is important to emphasize that the sieving tests are not accurate and, therefore, are not able to define small changes in the shape of the grains of tested polymers. Basically, it indicates relatively large changes in the size of analyzed particles.

Nevertheless, the absence of major changes or formation of fine fractions evidence that there was no relevant alteration in PET grains size, although PMO sample aspect indicates major polymer degradation. These observations are also supported by SEM results, presented below.

$\underline{\text { Table 1. Mass loss after chemical exposure at } 24.1 \mathrm{MPa} \text { and } 70^{\circ} \mathrm{C}}$.

\begin{tabular}{ccccc}
\hline Polymer & Chemicals & $\begin{array}{c}\text { Initial } \\
\text { Mass }(\mathbf{g})\end{array}$ & $\begin{array}{c}\text { Final Mass } \\
(\mathbf{g})\end{array}$ & $\Delta \mathbf{m}(\mathbf{\%})$ \\
\hline Virgin PET & Organic & 200 & 200.7 & 0.2 \\
$\begin{array}{c}\text { Recycled } \\
\text { PET }\end{array}$ & Solvents & 200 & 199.8 & 0.1 \\
PMO & & & & \\
Virgin PET & $\mathrm{HCl}$ & 200 & 199.9 & 0.0 \\
Recycled & & 200 & 182.8 & 8.6 \\
PET & & & 184.2 & 7.9 \\
PMO & & 200 & 72.1 & 64.0 \\
Virgin PET & Trilon CK & 200 & 199.3 & 0.3 \\
Recycled & & 200 & 199.8 & 0.1 \\
PET & & & & \\
PMO & & 200 & 198.3 & 0.8 \\
\hline
\end{tabular}

\subsection{SEM}

SEM micrographs obtained before and after subjecting the polymers to chemical exposure under test conditions are presented in Figure 2. The images show, in detail, that there were no evident changes on the surface of the grains of both virgin and recycled PET, in all chemicals tested. Considering the sensitivity of PET to hydrolysis in very acidic or alkaline media ${ }^{[1-14]}$, the small attacks suffered by the recycled and virgin samples under test conditions can be attributed to the relatively low temperature in a short exposure period of time ${ }^{[13]}$, both parameters derived from the observed operational oil well conditions ${ }^{[7]}$.

SEM analysis strongly reinforces the potential application of this material as sand control agent, evidencing the suitability of the recycled compound in a very significant application.

PMO sample, in turn, was strongly attacked, with remarkable changes in the shape of grains, especially in the acid medium, in which smaller and brittle grains were generated induced by the degradation ${ }^{[16-18]}$. In oil wells, those particles can block the pores formed by the polymer grains package, thereby reducing its permeability and preventing hydrocarbon or water flow, which is totally undesirable for a sand control agent ${ }^{[5]}$.

\subsection{SEC}

Table 2 presents the values of number average $\left({ }^{-} M_{n}\right)$, mass average $\left({ }^{-} \mathrm{M}_{\mathrm{w}}\right)$ molecular mass and polydispersity index $\left({ }^{-} \mathrm{M}_{\mathrm{w}} / \mathrm{M}_{\mathrm{n}}\right)$ obtained by size exclusion chromatography (SEC) for PET and PMO samples. Taking into account the sensitivity of the technique, the results showed that there were no marked changes, neither on the molecular mass

\section{Granulometric analisys \\ PET virgin (PET V) PET recycled (PET R) \\ PMO}

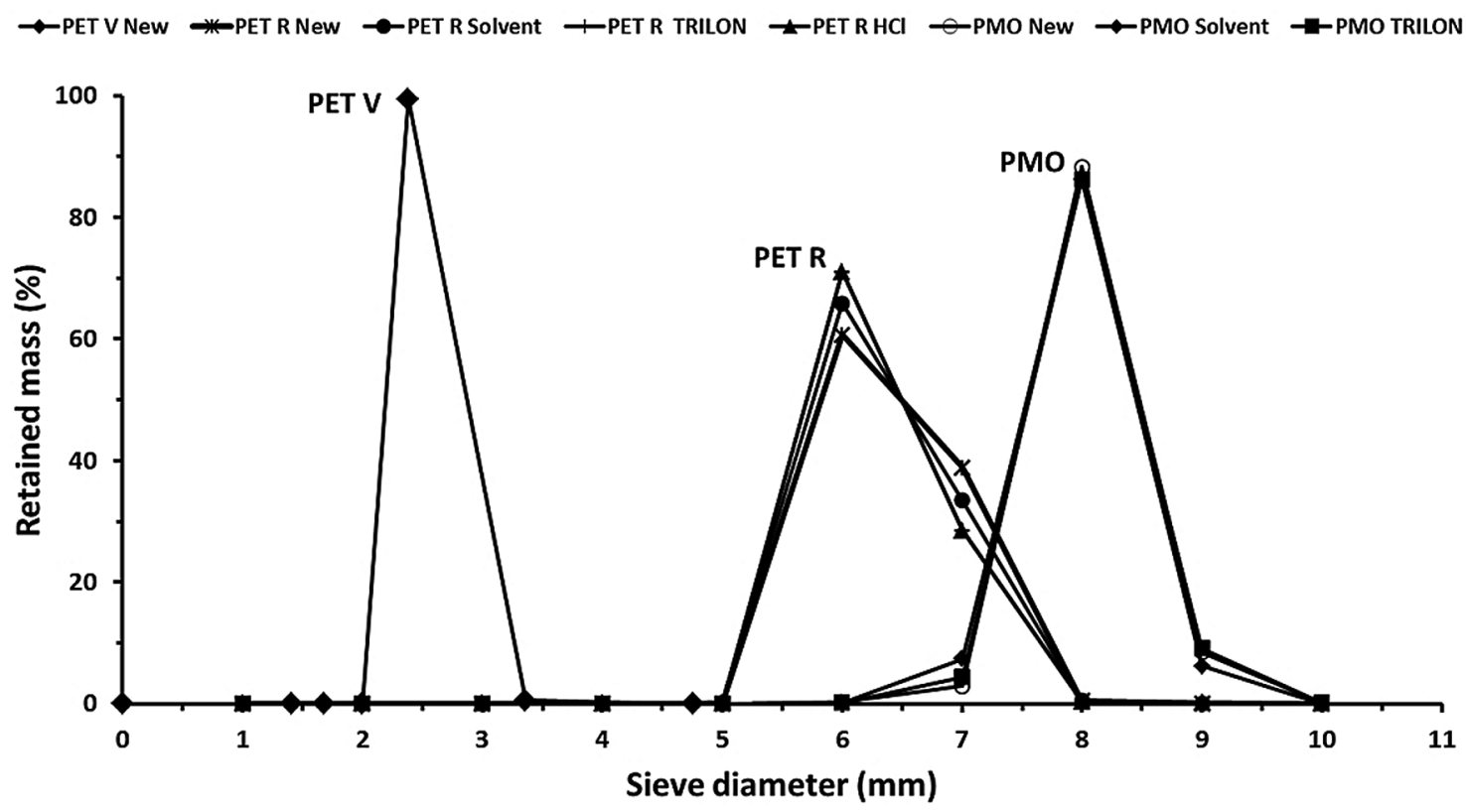

Figure 1. Granulometric curves for PET (virgin and recycled) and PMO samples after chemical exposure, at $24.1 \mathrm{MPa}$ and $70{ }^{\circ} \mathrm{C}$. 

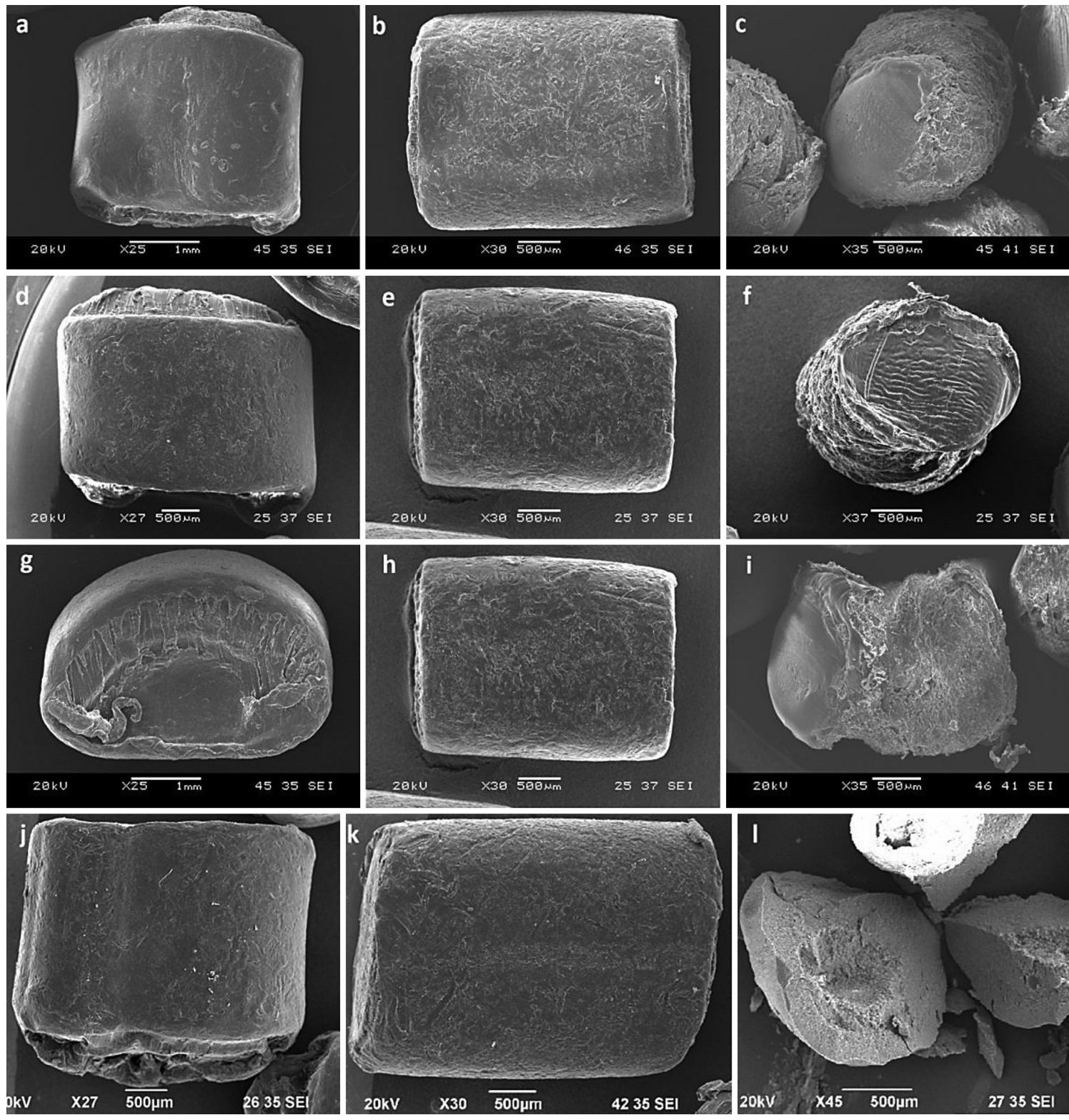

Figure 2. Micrographs obtained before chemical exposure ((a) $\operatorname{PET}_{\text {vir }}(25 \mathrm{x})$; (b) $\mathrm{PET}_{\text {rec }}$ (30x); (c) PMO (35x)) and after chemical exposure at 24.1 MPa and $70^{\circ} \mathrm{C}$ for $24 \mathrm{~h}$ to solvents; ((d) $\mathrm{PET}_{\text {virgin }}(27 \mathrm{x})$; (e) PET $\mathrm{Pec}_{\text {rec }}$ (30x); (f) PMO (37x)); $96 \mathrm{~h}$ to Trilon CK 10\%; ((g) PET (25x); (h) PET $_{\text {rec }}$ (30x); (i) PMO (35x)) and 24 h to HCl 15\%; ((j) PET $_{\text {vir }}$ (27x); (k) PET $_{\text {rec }}$ (30x); (l) PMO (45x)).

Table 2. Number average $\left({ }^{-} M_{n}\right)$, mass average $\left({ }^{-} M_{w}\right)$ molecular mass and polydispersity index $\left({ }^{-} M_{w} / M_{n}\right)$ of virgin and recycled PET samples, and PMO, before and after chemical exposure under test conditions.

\begin{tabular}{cccccccccc}
\hline \multirow{2}{*}{ Chemicals } & \multicolumn{3}{c}{$\mathbf{P E T}_{\mathrm{vir}}$} & \multicolumn{3}{c}{$\mathbf{P E T}_{\mathrm{rec}}$} & \multicolumn{3}{c}{ PMO } \\
\cline { 2 - 10 } & $-\mathbf{M}_{\mathbf{n}}$ & $-\mathbf{M}_{\mathbf{w}}$ & $-\mathbf{M}_{\mathbf{w}} / \mathbf{M}_{\mathbf{n}}$ & $-\mathbf{M}_{\mathbf{n}}$ & $-\mathbf{M}_{\mathbf{w}}$ & $-\mathbf{M}_{\mathbf{w}} / \mathbf{M}_{\mathbf{n}}$ & $-\mathbf{M}_{\mathbf{n}}$ & $-\mathbf{M}_{\mathbf{w}}$ & $-\mathbf{M}_{\mathbf{w}} / \mathbf{M}_{\mathbf{n}}$ \\
\hline As received & 43900 & 81600 & 1.9 & 37900 & 61600 & 1.6 & 119902 & 259661 & 2.2 \\
Trilon CK & 38600 & 64900 & 1.7 & 36600 & 63000 & 1.7 & 138708 & 252964 & 1.8 \\
HCl & 42700 & 66600 & 1.6 & 40300 & 60900 & 1.5 & & Insoluble \\
\hline
\end{tabular}

values nor on the polydispersity of both virgin and recycled PET samples after chemical exposure.

PMO sample presented a similar behavior of PET when exposed to the Trilon CK solution but it was strongly attacked by $\mathrm{HCl}$. As a consequence of the acid exposure, PMO grains became extremely brittle and insoluble in the SEC solvent (HFIP), preventing the realization of further chromatographic analysis. Strong acids produce hydrolytic 
degradation of polyacetals like PMO, and the mechanism involves changes in the polymer surface ${ }^{[16-18]}$ which can, at least in some extent, explain the observed effect over the solubility of PMO in HFIP.

The hydrolysis caused by acid exposure on PMO is described in the literature ${ }^{[14,16]}$ explaining the observed effects on $\mathrm{PMO}$ grains exposed to $\mathrm{HCl}$. Further researches, necessary to completely explain the hydrolysis effect on the solubility of PMO in HFIP, exceed the scope of this study and, therefore, were not performed.

Although being a polymer susceptible to hydrolysis ${ }^{[13]}$, PET samples experienced just smaller effects after exposure to both, alkaline and acid media.

\subsection{Mechanical resistance of the polymeric gravel pack}

There are several ways of testing the mechanical properties of a thermoplastic, however, none of them better represent the mechanical stress to which it will be subjected, when applied as gravel pack, as the API tes ${ }^{[9,10]}$, designed specifically to simulate the confinement conditions observed in oil well environment. Differently from the hydrostatic pressure, simulated in the chemical tests, the forces are applied in just one direction, allowing the gravel pack deformation. If a continuous deformation is observed, the porosity created by the space among grains collapses and a progressive reduction in the permeability is observed ${ }^{[3,9,10]}$. In open hole gravel pack, those forces are produced by the tendency of the formation to close around the gravel pack due to mechanical accommodation ${ }^{[2]}$.
The polymers were tested before and after chemical exposure, so the effects of conventional oil well chemical treatments over PMO, recycled PET and virgin PET mechanical properties could be observed. The initial variations, observed in the curves, were due to the plastic characteristics of the tested material that produces small changes in the thickness and porous structure of the polymer grain layer. The stabilization of grain layer can be seen in the pack thickness curve that presented a constant profile after a few minutes of test. A progressive reduction in the permeability or in the layer thickness would indicate poor mechanical resistance while stabilization in those polymeric gravel pack properties represents good resistance to the confinement conditions, and, therefore, suitability for the use in sand control systems.

The results indicated that all tested PET types maintain their mechanical resistance in acceptable levels, meaning that the chemical exposure did not attack those polymers significantly under the test conditions. Therefore, PET polymers prove to be adequate as sand control agent.

PMO, also, have shown good resistance to solvents and Trilon $\mathrm{CK}$, but was not tested with $\mathrm{HCl}$ due to the high sensitivity to acid attack, observed in the previous assays. The test results can be observed in Figures 3 and 4 .

It is important to note that, although the mechanical test presents qualitative characteristics, permeability stabilization in acceptable levels is a good indication that the well environment will not produce significant collapse of the polymeric gravel pack pore structure, therefore, will not cause significant impairment to hydrocarbon production $^{[3,9,10]}$.

Polymeric gravel pack permeability without chemical exposure $\left(70^{\circ} \mathrm{C} / 13.8 \mathrm{MPa}\right)$

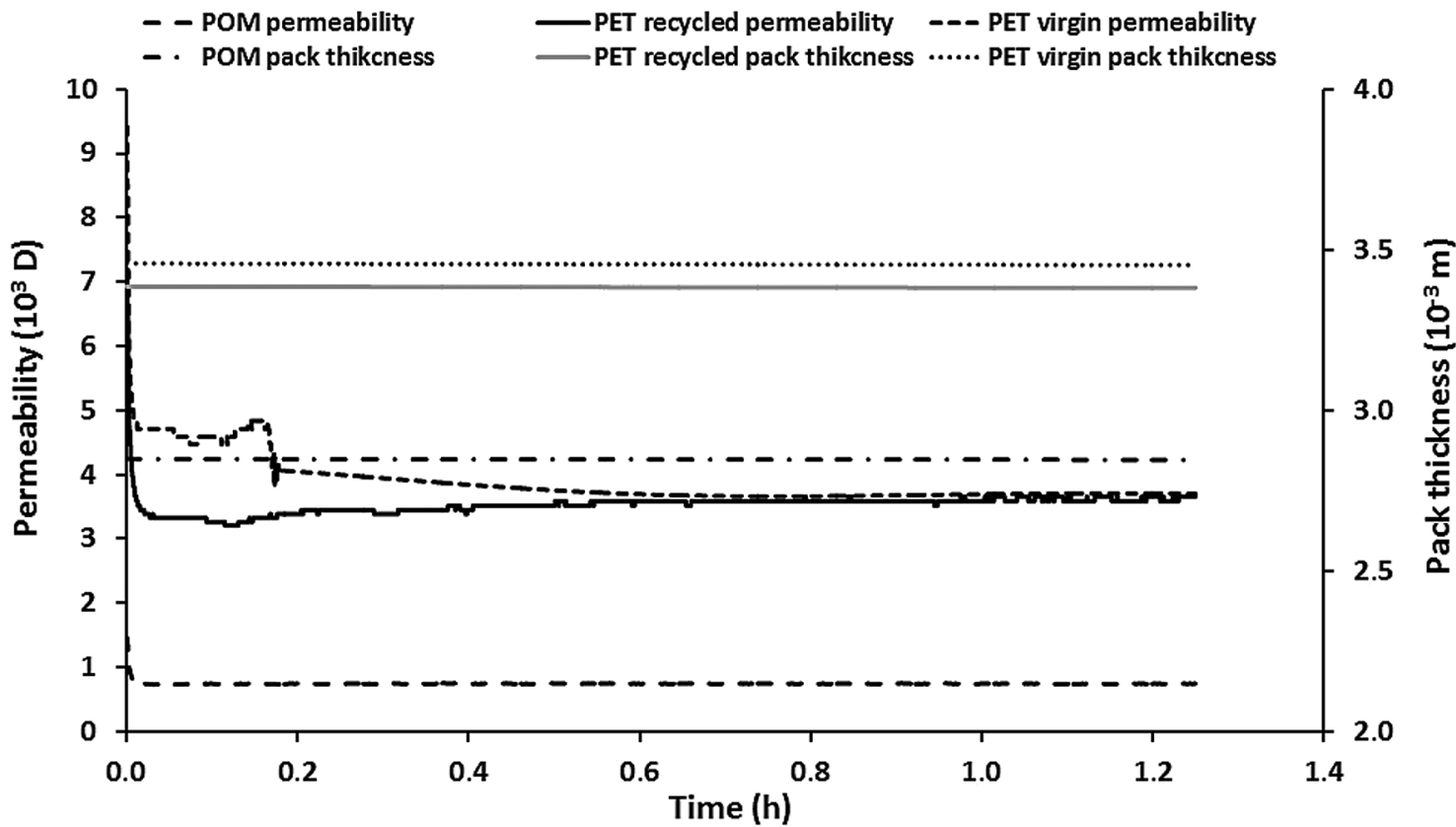

Figure 3. $\mathrm{PMO}, \mathrm{PET}_{\mathrm{rec}}$ and $\mathrm{PET}_{\text {vir }}$ gravel pack permeability tested under $70^{\circ} \mathrm{C}$ and a confinement pressure of $13.8 \mathrm{MPa}$, before chemical exposure. 


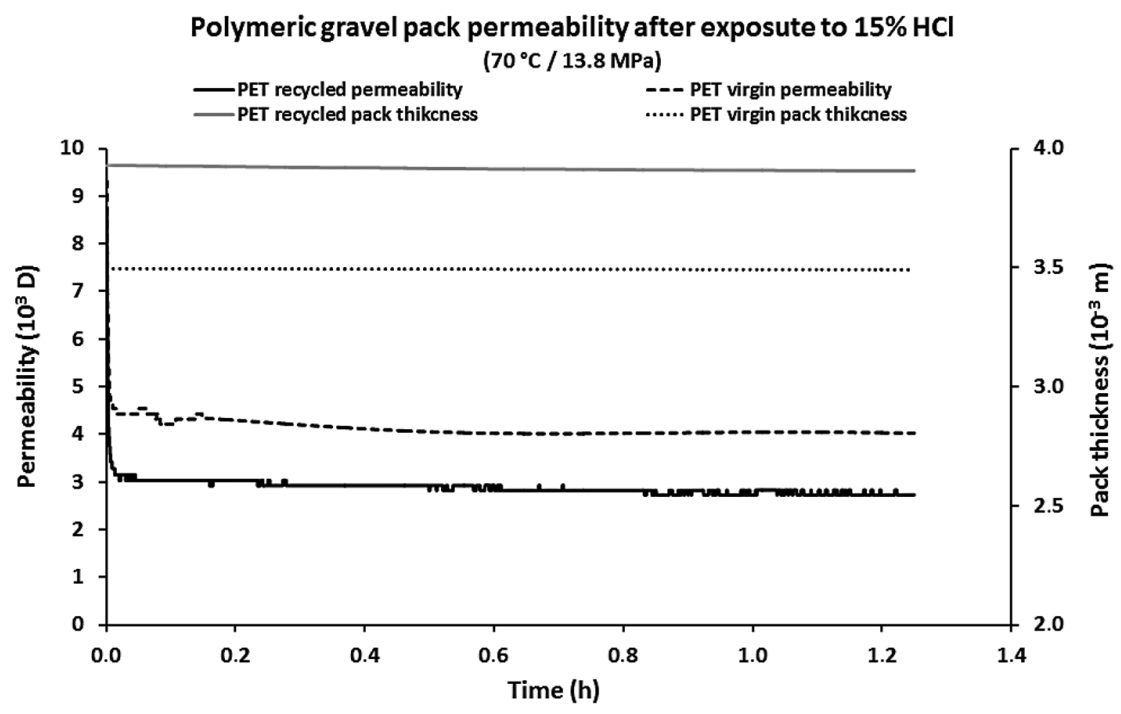

Polymeric gravel pack permeability after exposute to $10 \%$ TRILON CK $\left(70^{\circ} \mathrm{C} / 13.8 \mathrm{MPa}\right)$

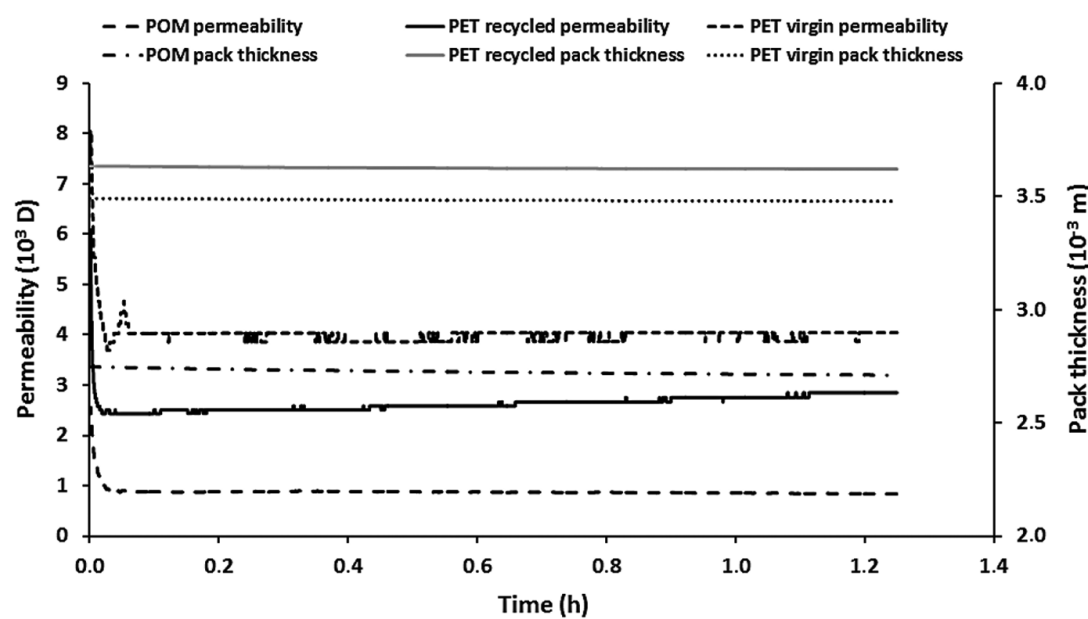

Polymeric gravel pack permeability after exposute to solvents $\left(70^{\circ} \mathrm{C} / 13.8 \mathrm{MPa}\right)$

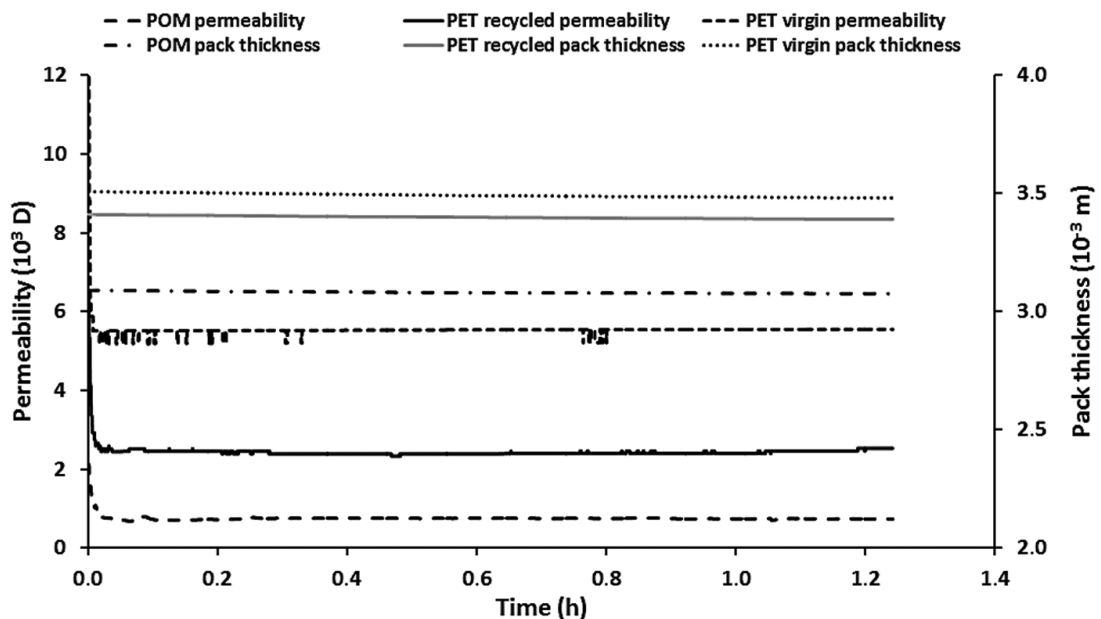

Figure 4. $\mathrm{PMO}, \mathrm{PET}_{\text {rec }}$ and $\mathrm{PET}_{\text {vir }}$ gravel pack permeability tested under $70^{\circ} \mathrm{C}$ and a confinement pressure of $13.8 \mathrm{MPa}$, after chemical exposure to Trilon CK $10 \%$ for 96 hours and to solvents for 24 hours, at $70{ }^{\circ} \mathrm{C}$ and $24.1 \mathrm{MPa}^{\mathrm{rir}} \mathrm{PET}_{\text {rec }}$ and $\mathrm{PET}_{\text {vir }}$ gravel pack permeability 24 hours of exposure to $\mathrm{HCl} 15 \%$ at $70{ }^{\circ} \mathrm{C}$ and $24.1 \mathrm{MPa}$. 


\section{Conclusions}

In the test conditions, simulating those observed in Campos Basin Oil wells, no significant effects of chemical exposure were observed on the PET samples. The mass loss was insignificant, without noticeable changes in number average $\left({ }^{-} M_{n}\right)$, mass average $\left({ }^{-} M_{w}\right)$ molecular mass and polydispersity $\left({ }^{-} \mathrm{M}_{\mathrm{n}} / \mathrm{M}_{\mathrm{w}}\right)$ of the tested samples. Likewise, the permeability of PET gravel packs presented a stable behavior when subjected to compression at oil well conditions (API test), evidencing that the use of PET (virgin and recycled) as gravel pack is viable.

Although poly (methylene oxide) (PMO) presents desirable properties for sand control agent as well, the observed acid resistance is not acceptable for its application in oil well environment, unless if applied only in wells without perspectives of undergoing acid treatments. Therefore, in general terms, this polymer is not recommended to be used in sand control systems.

The conclusions of the previous work ${ }^{[1]}$ were reinforced by the results obtained in the short term exposure tests, i.e., the new proposed use for recycled PET aggregates value to this material, since, as a sand control agent, there is no necessity of any additional treatment, besides the conventional recycling process ${ }^{[19-21]}$. That also improves PET recycling attractiveness in general, contributing to environment preservation.

\section{Acknowledgements}

The authors wish to thank Petrobras for the permition to publish this work and also Centro de Pesquisas e Desenvolvimento Leopoldo Américo Miguez de Mello (CENPES/PETROBRAS) and Instituto de Química/ Universidade Federal do Rio de Janeiro (IQ/UFRJ) for the analysis.

\section{References}

1. Pereira, A. Z. I., \& Delpech, M. C. (2012). Thermal and mechanical evaluation of the stability of recycled poly(ethylene terephthalate) applied as sand control agent in petroleum wells. Polymer Degradation \& Stability, 97(7), 1158-1163. http:// dx.doi.org/10.1016/j.polymdegradstab.2012.03.045.

2. Roegiers, J. C., \& Thiercelin, M. C. (2000). Formation characterization: rock mechanics. In J. M. Economides, K. G. Nolte (Eds.), Reservoir stimulation (pp. 3.1-3.8). West Succex: John Wiley \& Sons.

3. Tiab, D., \& Donaldson, E. C. (2012). Petrophysics: theory and practice of measuring reservoir rock and fluid transport properties. Walthan: Gulf Publishing.

4. Carlson, J., Gurley, D., King, G., Price-Smith, C., \& Waters, F. (1992). Sand control: why and how. Oilfield Review, 41-53. Retrieved in 10 February 2014, from http://www.slb.com/ / media/Files/resources/oilfield_review/ors92/1092/p41_53.pdf

5. Burton, R. C., Mackinley, W. M., Hodge, R. M., \& Landrum, W. R. (1998). Evaluating completion damage in high-rate, gravel-packed wells. Society of Petroleum Engineers, 13(4), 259-265. Retrieved in 10 February 2014, from https://www. onepetro.org/journal-paper/SPE-52893-PA

6. Nguyen, P. D., \& Norman, L. R. (2005). US Patent No 20050284631. Washington: U.S. Patent and Trademark Office.

7. Daher, J. S., Gomes, J. A. T., Rosario, F. F., Bezerra, M. C., Amorim, V. C. F., Dumas, G. E., \& Oliveira, S. E. A. P. (2006). Field experience to assess efficiency of scale dissolver treatment in a subsea deep water well. In SPE International Oilfield Scale Symposium. Aberdeen: Society of Petroleum Engineers. Retrieved in 10 February 2014, from https://www. onepetro.org/conference-paper/SPE-100653-MS

8. Pereira, A. Z. I., Calderon, A., Chagas, C. M., \& Pinto, E. A. (2007). Recent advances in deepwater horizontal injector wells acidizing in Campos Basin. In European Formation Damage Conference. Scheveningen: Society of Petroleum Engineers. Retrieved in 10 February 2014, from https://www.onepetro. org/conference-paper/SPE-107787-MS

9. American Petroleum Institute. (2008). API RP 19C: measurement of properties of proppants used in hydraulic fracturing and gravel-packing operations. Washington.

10. American Petroleum Institute. (2008). API RP 19D: measuring the long-term conductivity of proppants. Washington.

11. Namboori, C. G. G., \& Haith, M. (1968). Steric effects in the basic hydrolysis of poly(ethylene terephthalate). Journal of Applied Polymer Science, 12(9), 1999-2005. http://dx.doi. org/10.1002/app.1968.070120901.

12. Mancini, S. D., \& Zanin, M. (2002). Influência de meios reacionais na hidrólise de PET pós-consumo. Polímeros: Ciência e Tecnologia, 12(1), 34-40. http://dx.doi.org/10.1590/ S0104-14282002000100010.

13. van Schoors, L. V. (2007). Hydrolytic aging of polyester (polyethylene terephthalate) geotextiles: state of the art assessment. Bulletin des Laboratoires des Ponts et Chaussées, 270, 133-154. Retrieved in 10 February 2014, from http:// www.geotech-fr.org/sites/default/files/revues/blpc/BLPC $\% 20$ 270-271\%20pp\%20133-154\%20Vouyovitch.pdf

14. Yoshioka, T., Sato, T., \& Okuwaki, A. (1994). Hydrolysis of waste PET by sulfuric acid at $150^{\circ} \mathrm{C}$ for a chemical recycling. Journal of Applied Polymer Science, 52(9), 1353-1355. http:// dx.doi.org/10.1002/app.1994.070520919.

15. Yoshioka, T., Okayama, N., \& Okuwaki, A. (1998). Kinetics of hydrolysis of PET powder in nitric acid by a modified shrinking-core model. Industrial \& Engineering Chemistry Research,37(2), 336-340. http://dx.doi.org/10.1021/ie970459a.

16. Ivanova, L. V., Pavlov, N. N., \& Zaikov, G. Y. (1976). Macrokinetic features of the degradation of polyoxymethylene blocks in aqueous solutions of mineral acids. Polymer Science URSS, 18(6), 1534-1542. http://dx.doi.org/10.1016/00323950(76)90353-1.

17. Pchelintsev, V. V., Sokolov, A. Yu., \& Zaikov, G. E. (1988). Kinetic principles and mechanisms of hydrolytic degradation of mono and polyacetals - A review. Polymer Degradation and Stability, 21(4), 285-310. http://dx.doi.org/10.1016/01413910(88)90017-1.

18. Kusy, R. P., \& Whitley, J. Q. (2005). Degradation of plastic polyoxymethylene brackets and the subsequent release of toxic formaldehyde. American Journal of Orthodontics and Dentofacial Orthopedics, 127(4), 420-427. http://dx.doi. org/10.1016/j.ajodo.2004.01.023. PMid:15821686.

19. La Mantia, F. P., \& Vinci, M. (1994). Recycling poly(ethyleneterephthalate). Polymer Degradation \& Stability, 45(1), 121-125. http://dx.doi.org/10.1016/0141-3910(94)901872.

20. Awaja, F., \& Pavel, D. (2005). Recycling of PET. European Polymer Journal, 41(7), 1453-1477. http://dx.doi.org/10.1016/j. eurpolymj.2005.02.005.

21. Associação Brasileira da Indústria do PET. (2014, May 15). Retrieved in 10 February 2014, from http://www.abipet.org. br/index.html 